\title{
Surgical treatment options for cerebral alveolar echinococcosis: Experience in six patients
}

Junyi W ang, Bowen Cai, Chao You

Department of Neurosurgery, West China Hospital, Sichuan University, China

Address for correspondence:

Mr. Chao You,

No. 37 Guoxue xiang, Chengdu,

Sichuang, 610041, P.R.China

E-mail:wangjunyi305@yahoo.cn

DOI: $10.4103 / 0028-3886.51284$

\begin{abstract}
Abstrad
Background: Cerebral alveolar echinococcosis (AE) is a rare but lethal parasitic disease. Its pathogenesis remains poorly understood. Currently there is no widely accepted methods for its surgical treatment. Aims: To discuss the surgical treatment options. Settings and Design: Hospital-based observational study. Materials and Methods: Patients who had surgery for cerebral AE during 200I and 2007 were the subjects of the study. According to the lesion location and volume, patients have been allocated to either massive resection group or radical piecemeal resection group. Postoperatively, all patients received long-term aldendazole therapy in view of the associated hepatic involvement and were follow-up in the clinic. Results: Of the six patients with cerebral AE who were operated during the study period, four had massive resection and two had radical piece meal resection. None of the patients had postoperative neurological worsening and there was improvement in the neurological status in all the patients except for the patient with blindness. Of the 4 patients in massive resection group, two patients died during the follow-up, one because of liver failure and the other due to hydrocephalus. The remaining four patients were back to their normal activities and none had recurrence of the disease during the follow-up. Conclusions: Although radical massive resection is generally regarded as the surgical method treatment for cerebral $\mathrm{AE}$, radical piecemeal resection can be a reasonable, effective alternative management option, especially when massive resection might result in unavoidable morbidity and mortality.
\end{abstract}

Key words: C erebral alveolar echinococcosis, echino coccus multilocularis, surgical treatment

\section{Introduction}

Cerebral alveolar echinococcosis (AE) is a rare life-threatening parasitic disease. Recent investigations have shown increasing prevalence of Echinococcus multilocularis posing a considerable risk in Central Europe, Japan, and China. ${ }^{[1-4]}$ Currently, radical resection is generally considered as the only method of surgical treatment. ${ }^{[5-8]}$ However, such an approach at times may be associated with considerable morbidity and mortality. This is much more so when the lesion location is in the brainstem or eloquent areas. We report our experience of surgical treatment for cerebral AE.

\section{Materials and M ethods}

Patients operated for cerebral AE between 2001 and 2007 at our hospital were the subjects of the study. All the patients were from north Sichuan, one of the high epidemic regions in China. Definitive diagnosis of cerebral AE was based on the clinical features, operative observations, and pathology. Serological testing for hydotid, EnzymeLinked ImmunoSorbent Assay (ELISA) was done in all the patients. All patients had computerized tomography (CT) and magnetic resonance imaging (MRI).

All patients underwent neurosurgery and were also put on albendazole therapy postoperatively. According to the 
localization and volume of the lesion, different surgical approaches were performed. Patients were followed-up postoperatively for the outcome of surgery.

\section{Results}

Six patients had surgery for cerebral AE during the study period. The median age was 39 years (range 20-60 years). The clinical features, surgical treatment, and outcome are summarized in Table 1. The main clinical presentations included headache, nausea, vomiting, recurrent seizures and focal neurological deficits. All the patients had associated hepatic involvement. Serological testing,(ELISA) was positive in five patients.

On CT scan,AE lesions appeared as hypodense or isodense, masses. Calcification and surrounding edema were some of the common features seen. Contrast enhancement was observed within the inflammatory reaction around the lesion [Figures 1 and 2]. On MRI lesions were hypo- or isointnse on T1-weighted images and were of heterogeneous intensity on T2-weighted images with surrounding peri-lesional edema. Contrast enhancement was seen around the lesion in the inflammatory zone [Figures 1 and 2].

\section{Surgical management}

All patients underwent operation by neurosurgery. According to the localization and volume of the lesion, different approaches were performed. Patients with lesions located in the cerebral hemispheres and with small volume, were allocated to massive resection group [Figure 1], The bone flaps were always larger than the cross section of the mass and were opened with high speed drill slowly and carefully. The dura were incised without using electrocoagulation, and any adhesions between the dura and the cerebral pia mater were separated with sharp dissection. The cortex overlying the lesion had to be opened with only spatula retractors. The incision in the cortex was larger than the lesion. Once the lesions were displayed, thin strips of cotton were inserted between the lesion and the surrounding cerebral parenchyma. The brain tissue was gently separated from the mass with spatula retractors and aspirators. Four patients underwent radical gross resection. On the other hand, in patients with lesions located in the eloquent areas or with giant volume (the radical piecemeal resection group), debulking resection was performed. The third patient with lesion in the brainstem received radical piecemeal resection via the lateral suboccipital approach. The fifth patient with large mass located in the anterior cranial base in the midline area underwent entire debulking resection through a left frontal craniotomy [Figures 2 and 3]. Once lesions were exposed, thin strips of cotton were immediately inserted around the mass to protect the surrounding cerebral tissue. Then, microsurgery was performed by an internal debulking to gradually shrink the size of the mass until complete removal was achieved, according to interface between the normal brain tissue and lesion. After removal of these lesions, the spaces were carefully washed with $10 \%$ hypertonic saline solution repeatedly, and the whole cavity was filled with $0.9 \%$ saline solution. Cautious and leak tight closure of the dura was performed at the end of the procedure.

Postoperatively, all patients received albendazole, $10 \mathrm{mg} / \mathrm{kg}$ body weight per day for lifetime as all the patients had associated inoperable liver involvement. Patients were given two weeks drug holiday for every four weeks of treatment. This was done to prevent cumulative drug toxicity if there is any.

\section{Outcome}

None of the patients had postoperative neurological worsening and all had improvement in the neurological

\begin{tabular}{|c|c|c|c|c|c|c|c|}
\hline $\begin{array}{l}\text { Age } \\
\text { (years)/ } \\
\text { sex (M/F) }\end{array}$ & $\begin{array}{l}\text { Clinical } \\
\text { presentation }\end{array}$ & Location of lesion & $\begin{array}{l}\text { Hepatic/ } \\
\text { pulmonary } \\
\text { invasion }\end{array}$ & $\begin{array}{l}\text { Serologic } \\
\text { test }\end{array}$ & $\begin{array}{l}\text { Surgical } \\
\text { treatment }\end{array}$ & $\begin{array}{c}\text { Follow-up } \\
\text { period (months) }\end{array}$ & Outcome \\
\hline $35 / \mathrm{M}$ & Persistent headache, & Right parietoccipital lobe & $+/+$ & + & $\begin{array}{l}\text { Radical massive } \\
\text { resection }\end{array}$ & 12 & $\begin{array}{l}\text { Died of liver } \\
\text { failure }\end{array}$ \\
\hline $46 / \mathrm{M}$ & nausea, vomiting & Left frontal lobe & $+/+$ & + & $\begin{array}{l}\text { Radical massive } \\
\text { resection }\end{array}$ & 18 & $\begin{array}{l}\text { Died of untreated } \\
\text { hydrocephalus }\end{array}$ \\
\hline $38 / \mathrm{M}$ & $\begin{array}{l}\text { Headache, nausea, } \\
\text { vomiting, epilepsy } \\
\text { seizure }\end{array}$ & $\begin{array}{l}\text { Left frontal lobe and } \\
\text { brainstem }\end{array}$ & $+/-$ & + & $\begin{array}{l}\text { Radical piecemeal } \\
\text { resection }\end{array}$ & 42 & Good \\
\hline $60 / M$ & $\begin{array}{l}\text { left face numbness } \\
\text { Epilepsy seizure }\end{array}$ & Right parietal lobe & $+/-$ & + & $\begin{array}{l}\text { Radical massive } \\
\text { resection }\end{array}$ & 12 & Good \\
\hline $20 / \mathrm{M}$ & $\begin{array}{l}\text { Persistent headache, } \\
\text { nausea, vomiting, } \\
\text { blindness }\end{array}$ & Anterior cranial base & $+/-$ & + & $\begin{array}{l}\text { Radical piecemeal } \\
\text { resection }\end{array}$ & 8 & $\begin{array}{l}\text { Good except for } \\
\text { blindness }\end{array}$ \\
\hline $35 / \mathrm{M}$ & Epilepsy seizure & $\begin{array}{l}\text { Bilateral frontal, temporal, } \\
\text { parietal lobe }\end{array}$ & $+/+$ & - & $\begin{array}{l}\text { Radical massive } \\
\text { resection }\end{array}$ & $\begin{array}{c}\text { (Drop out after } \\
\text { Wenchuan Earth- } \\
\text { quake) } 12\end{array}$ & Good \\
\hline
\end{tabular}




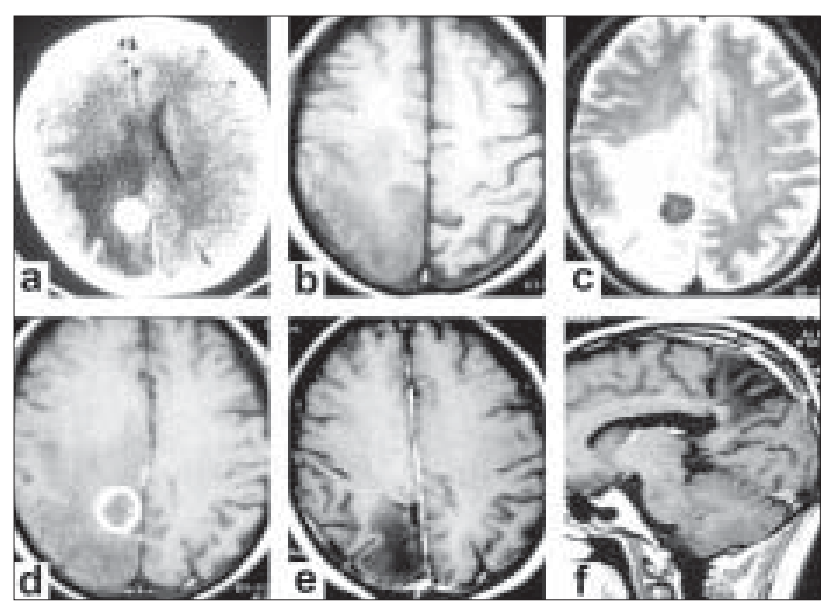

Figure 1: Preoperative (a-d) CT and MRI showing a right parietal parasggital enhancing mass lesion with perilesional edema. Postoperative MRI (e-f) of the same patient showing no recurrence of the lesion at 12 months of follow-up

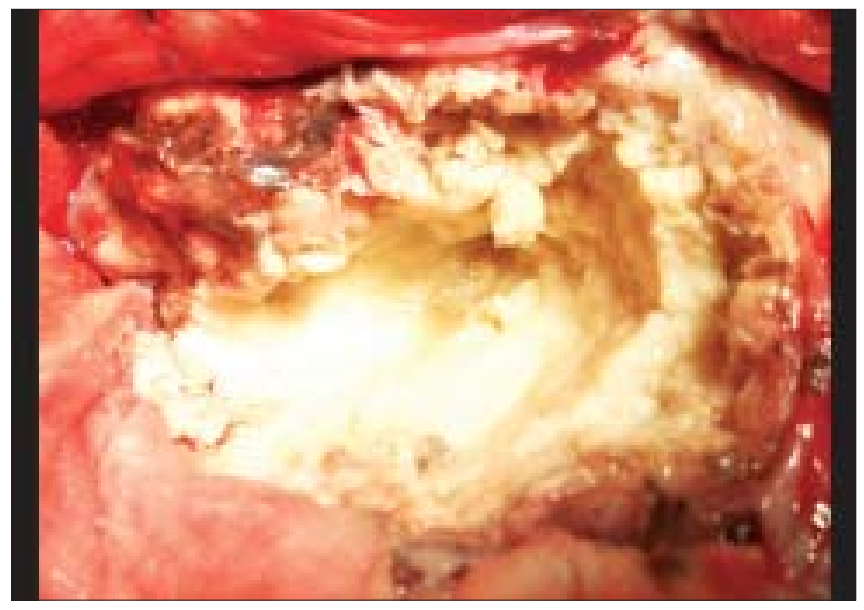

Figure 3: The exsanguine Swiss cheese lesion

deficits except the patient with blindness. At subsequent clinical evaluation, the patients remained neurologically asymptomatic except the patient with blindness. There were two deaths, one due to liver failure and the other related to untreated hydrocephalus at twelfth and eighteenth months of operation respectively. The remaining patients are back to their normal activity.

\section{Discussion}

In contrast to cysts echinococcosis (CE), the prevalence of cerebral AE in humans is quite rare. It is still the widespread, life-threatening parasitic infection prevalent in the Northern Hemisphere: Central Europe, Turkey, Russia, Japan, Alaska, North America, and China. ${ }^{[3,9]}$ Moreover, recent investigations have shown that some factors such as increasing prevalence of infection in fox population, the closer proximity between foxes and humans, and spillover of E. multilocularis infection
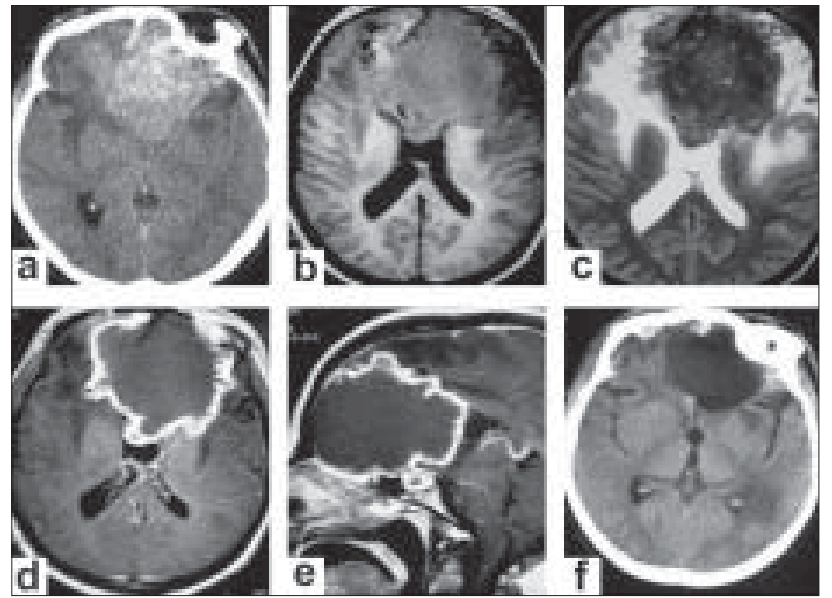

Figure 2: Preoperative CT and MRI (a-e) showing left frontal heterogeneous contrast enhancing mass lesion with displacement of the ventricles. Postoperative CT (f) of the same patient showing complete excision of the lesion

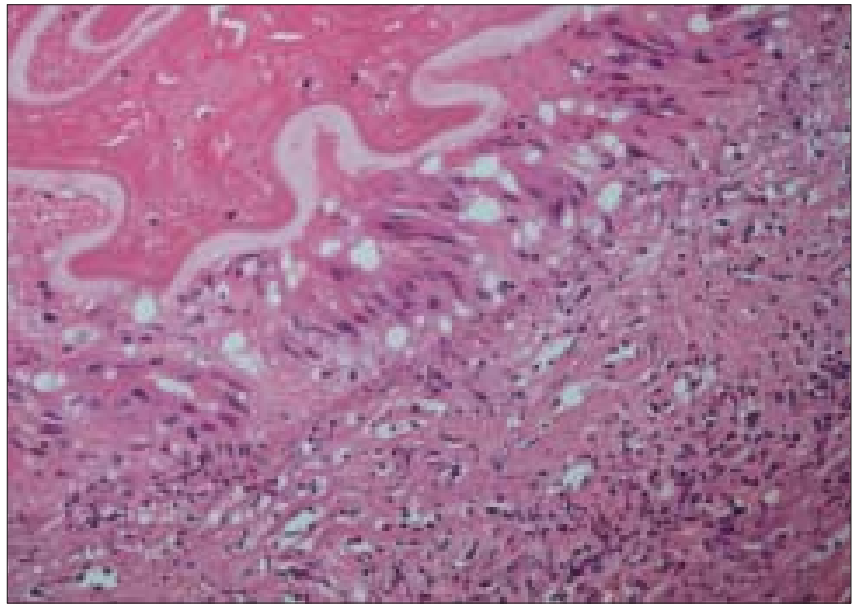

Figure 4: Photomicrograph showing an intense granulomatous reaction without germinal layer and protoscolex $(H \& E, \times 400)$

from wild carnivores to domestic animals, might pose a considerable public health risk, ${ }^{[1,3]}$ Intracranial AE account for $\sim 1 \%$ of all cases of $\mathrm{AE}$ and is generally considered to be fatal. ${ }^{[9]}$

The life cycle of E. M ultilocularis involves carnivores: Fox, dog, wolf, and occasionally cat as definite hosts and herbivores: Rodent, pig, monkey, and hare, as intermediate hosts. ${ }^{[3,9,10]}$ Humans are just incidental and aberrant intermediate hosts, who are usually infected by ingestion of ova from feces of carnivores via uncooked, contaminated green vegetables, water, and fruits ${ }^{[3,5,9,11]}$ In the duodenum, these ova lose their membrane and the oncosphere is released from the keratinized embryophore and pass through the host's intestinal wall into the liver via the portal circulation. Although Reuter et al., reported two cases with extrahepatic $\mathrm{AE}$ without liver involvement, the primary location of the $\mathrm{AE}$, as a general rule, is always in the 
liver. ${ }^{[4,12,13]}$ The capacity of the larva for exogenous proliferation enables it to initiate (usually via the bloodstream) the formation of distant metastases in lungs, brain, bones, kidneys, and other organs. ${ }^{[9]}$ Cerebral metastases occurs in only $1 \%$ of the infected patients. ${ }^{[14]}$ All the patients in this study had inoperable liver invasion, thus indicating that the cerebral $\mathrm{AE}$ in these patients was a secondary metastasis.

In CE caused by E. grannulosus, the cyst wall is composed of two layers, the outer layer, laminated hyaline membrane (ectocyst) and an inner layer, germinal epithelium (endocyst). ${ }^{[15]}$. Where as human AE is a heterogeneous non-capsulated solid mass. It grows by exogenous and tumor-like proliferation and lacks a laminated membrane. The lack of laminated membrane allows the parasite to invade the host tissue in alveolilike pattern. ${ }^{[16]}$ In case of CE, in the inner germinal layer pullulation occurs always towards the cavity, producing scolices, daughter cysts, and ever grand-daughter cysts (in various stages of development). Thus while operating CE lesions, various techniques, including Dowling technique, should be employed for the safe delivery of the cerebral cysts without spilling their contents to avoid recurrence. Moreover, the wall is white, smooth, soft to touch, and elastic so that it can be totally removed through an incision smaller than its diameter without rupture. ${ }^{[17]}$ These techniques allow the neurosurgeons to remove the $\mathrm{CE}$ lesion. However, the techniques may not be applicable for patients with cerebral AE lesion

Studies have shown proliferation and metastases formation of larval E. muitilocularis in the natural intermediate host, $M$ eriones unguiculatus. ${ }^{[18]}$ However the pathogenesis of human cerebral metastases is not yet clear. Moreover, it is not clear whether or not the cerebral metastases contain protoscolex ${ }^{[5,6,8,12,19]}$ In the excised specimens of our patients, neither protoscolex nor germinative membranes could be identified [Figure 4]. In the intermediate host the growth of protoscolex is quite rapid, 2 to 4 months, where as in human $\mathrm{AE}$ the formation and proliferation of protoscolex is very slow over 5 to 15 years. ${ }^{[4,20]}$ Some researchers feel that in human, the parasite does not form protoscolex and is made of a thin cuticle with nongerminative membrane. ${ }^{[21,22]}$ These observations suggests that incision of cerebral AE may not be the cause for larval distant metastasis. Two of our patients who had piecemeal resection, had no recurrence of the disease at 8 and 42 months of follow-up respectively and have resumed normal activities. We feel that piecemeal resection may be the procedure for lesions located in the eloquent areas. Of course, the optimum treatment of cerebral metastasis is surgical resection using radical procedures. But there is a risk of post-procedural major neurological deficits with radical procedure.
In an attempt to balance the advantage of an aggressive surgical resection against the risk of associated significant morbidity and mortality, surgical procedures, in our opinion, have to be adapted to individual situation, such as stage of the disease, location and volume of the lesion, and other systemic factors. In case of small lesions located in the non-eloquent areas, radical massive resection should be the procedure of choice. The exact size and position of the lesion should be mapped on the surface of the scalp, and the bone flap should be larger than the cross section of the mass. And special attention should be taken on opening the bone flap as well as dura. Moreover, the incision of substantia corticalis must be larger than the lesion.

However, it is impossible for the lesion to be removed when it is located in the brainstem and eloquent areas, without damaging the surrounding brain tissue. In these patients, piecemeal resection is the only option. Fortunately, they are really rare. To the best of our knowledge, no paper on piecemeal resection of cerebral $\mathrm{AE}$ has been reported so far. We performed piecemeal resection in two of the six patients with cerebral $\mathrm{AE}$, and both the patients were followed up for 8 and 42 months, respectively. None of them had recurrence of the disease. We feel radical piecemeal resection along with albendazole therapy is probably the best treatment option for patients with large volume lesions and also for lesions located in the eloquent areas and brainstem.

Long-term chemotherapy was essential component of treatment in our patients after radical resection of the cerebral lesions as they had inoperable hepatic primary infection. Albendazole is a parasitostatic agent against E. multilocularis metacestode, it can reduce the viability of protoscolices and cysts, and also its metabolite, albendazole sulfoxide, is active against the larval cestodes. ${ }^{[4,23]}$ Earlier experience with albendzole suggests that the drug is effective in killing E. multilocularis in few cases. ${ }^{[22]}$ We preferred to use the interruptedtreatment regimen because of the hepatotoxicity of albendazole and also extensive hepatic involvement in these patients.

In conclusion, human $\mathrm{AE}$ is a disease associated with serious complications and significant morbidity and mortality, especially cerebral AE. Even though surgical treatment for cerebral metastasis is palliative in patients with inoperable primary disease, it along with chemotherapy may relieve the symptoms and prolong the life. Radical massive resection is the optimal, but in certain cases, like brainstem lesions and lesions in the eloquent areas, where radical massive resection is not possible, radical piecemeal resection is a reasonable and effective alterative treatment strategy. 


\section{References}

1. Kamiya M, Lagapa JT, Nonaka N, Ganzorig S, Oku Y, Kamiya H. Current control strategies targeting sources of echinococcosis in Japan. Rev Sei Tech 2006;25:1055-65.

2. MeManus DP, Zhang W, Li J, Bartley PB. Echinococeosis. Lancet 2003;362:1295-305.

3. Romig T. Epidemiology of echinococessis. Langenbecks Arch Surg 2003;388:209-17.

4. Pawłowski ZS, Eckert J, Vuitton DA, Ammann RW, Kern P, Craig PS, et al. Echinococesosis in humans: Clinical aspects, diagnosis and treatment. In: Eckert J, Gemmell MA, Meslin FX, Pawłowski ZS, editors. WHO/OIE manual on echinococeosis in humans and animals: A public health problem of global concern. World Organisation for Animal Health and World Health Organization; 2001. p. 20-69.

5. Algros MP, Majo F, Bresson-Hadni S, Koch S, Godard J, Cattin F, et al. Intracerebral alveolar echinococcosis. Infection 2003;31:63-5.

6. Aydin Y, Barlas O, Yolass C, Aydin IH, Ceviz A, Aladağ A, et al. Alveolar hydatid disease of the brain: Report of four cases. J Neurosurg 1986;65:115-9.

7. Bensaid AH, Dietemann JL, de la Palavesa MM, Klinkert A, Kastler B, Gangi A, et al. Intracranial alveolar echinococcosis: CT and MRI. Neuroradiology 1994;36:289-91.

8. Qiu MD, Hun ZS, Liu SC, Wen LC, Wang SH, Bao LX. Intracranial alveolar echinococeosis in China: Discussion of surgical treatment. Acta Neurochir (Wien) 1986;82:123-7.

9. Raether W, Hänel H. Epidemiology, clinical manifestations and diagnosis of zoonotic cestode infections: An update. Parasitol Res 2003;91:412-38.

10. Xiao N, Li TY, Qiu JM, Nakao M, Chen XW, Nakaya K, et al. The Tibetan hare Lepus oiostolus: A novel intermediate host for Echinococcus multilocularis. Parasitol Res 2004;92:352-3.

11. Garcia HH, Moro PL, Schantz PM. Zoonotic helminth infections of humans: Echinococeosis, cysticereosis and fascioliasis. Curr Opin Infect Dis 2007;20:489-94

12. Reuter S, Seitz HM, Kern P, Junghanss T. Extrahepatic alveolar echinococcosis without liver involvement: A rare manifestation. Infection 2000;28:187-92.

13. Smith DM, Rickman LS. Echinococcosis: A drop of water-review on human disease, diagnosis, and management. Infect Dis Clin Pract 2001;10:355-9.

14. Bresson-Hadni S, Vuitton DA, Bartholomot B, Heyd B, Godart D, Meyer JP, et al. A twenty-year history of alveolar echinococcosis: Analysis of a series of 117 patients from eastern France. Eur J Gastroenterol Hepatol $2000 ; 12: 327-36$

15. Haddad FS, Haddad GF. Hydatid disease of the central nervous system, personal experience: Its appearance, management, and outcome in the brain and spine, Neurosurg Q 2005;15:33-41.

16. Craig P. Echinococeus multilocularis. Curr Opin Infect Dis 2003;16: $437-44$.

17. Izci Y, Tüzün Y, Seçer HI, Gönül E. Cerebral hydatid cysts: Technique and pitfalls of surgical management. Neurosurg Focus 2008;24:E15.

18. Mehlhorn H, Eckert J, Thompson RC. Proliferation and metastases formation of larval Echinococeus muitilocularis: II, Ultrastructural investigations. Z Parasitenkd 1983;69:749-63.

19. Piotin M, Cattin F, Kantelip B, Miralbès S, Godard J, Bonneville JF. Disseminated intracerebral alveolar echinococcosis: CT and MRI Neuroradiology 1997;39:431-33.

20. Kern P, Bardonnet K, Renner E, Auer H, Pawlowski Z, Ammann RW, et al. European echinococessis registry: Human alveolar echinococeosis, Europe, 1982-2000. Emerg Infect Dis 2003;9:343-49.

21. Khuroo MS. Hydatid disease: Current status and recent advances. Ann Saudi Med 2002;22:56-64.

22. Wilson JF, Rausch RL, Wilson FR. Alveolar hydatid disease: Review of the surgical experience in 42 cases of active disease among Alaskan Eskimos. Ann Sur 1995;221:315.

23. Liu LX, Weller PF. Antiparasitic drugs. N Engl J Med 1996;334: 1178-84.

Accepted on 04-04-2009

Source of Support: Nil, Conflict of Interest: None declared.

\section{Dispatch and return notification by E-mail}

The journal now sends email notification to its members on dispatch of a print issue. The notification is sent to those members who have provided their email address to the association/journal office. The email alerts you about an outdated address and return of issue due to incomplete/incorrect address.

If you wish to receive such email notification, please send your email along with the membership number and full mailing address to the editorial office by email. 